\title{
ALFABETIZAÇÃO, LIVROS DIDÁTICOS E EDUCAÇÃO AMBIENTAL: PRODUÇÃO DE SUJEITOS NA CONTEMPORANEIDADE
}

\author{
LITERACY , TEXTBOOKS, AND ENVIRONMENTAL EDUCATION: \\ THE PRODUCTION OF SUBJECTS IN CONTEMPORARY TIMES
}

ALFABETIZACIÓN, EDUCACIÓN Y EDUCACIÓN AMBIENTAL LIBROS: LA PRODUCCIÓN DE LOS SUJETOS EN LOS TIEMPOS CONTEMPORÁNEOS

\author{
Lorena Santos da Silva ${ }^{i}$ \\ Paulo Corrêa Henning ${ }^{i i}$ \\ Virgínia Tavares Vieira ${ }^{\text {iii }}$
}

\section{RESUMO}

O presente estudo busca analisar verdades sobre Educação Ambiental proferidas em Livros Didáticos avaliados pelo MEC no triênio dos anos de 2013 a 2015 que compõem o ciclo de alfabetização. Parte-se do pressuposto de que os Livros Didáticos são artefatos culturais que colocam em circulação verdades sobre EA. Dessa forma, se utiliza os estudos de Michel Foucault e algumas ferramentas da Análise do Discurso - enunciações, verdade e formações discursivas. Entendemos que as práticas discursivas estão na ordem do discurso ambiental, potencializando certo modo de agir no meio ambiente e na natureza. Os ditos ambientais atuam nas linhas de subjetivação dos sujeitos ecológicos, formando um indivíduo concatenado ao tempo contemporâneo. Alguns dos achados desta pesquisa evidenciam o distanciamento da abordagem transdisciplinar, bem como a circulação de enunciações que apresentam algumas temáticas ambientais a partir do naturalismo e do discurso da crise ambiental.

PALAVRAS-ChAVE: Educação ambiental. Livros didáticos. Verdade.

\section{ABSTRACT}

This study seeks to analyze truths about environmental education that have been said in textbooks evaluated by the Ministry of Education in the last three years 2013 a 2015, which form the literacy cycle. We base our study on the assumption that textbooks are cultural artifacts that put into circulation truths about environmental education. We employ the studies of the Michel Foucault and some tools of discourse analysis Discourse Analysis - enunciations, the truth and discursive formations. We understand that these discursive practices are the order of the environmental discourse, strengthening a way to act on the environment and nature. Those environmental sayings act in the subjectification lines of ecological subjects, forming an individual connected to contemporary times. Some of our findings in this research show us the detachment of the transdisciplinary approach, and also the existence of enunciations that have some environmental issues based on naturalism and environmental crisis discourse.

KEYWORDS: Environmental education. Textbooks. Truth.

\section{RESUMEN}

Este estudio busca analizar verdades sobre educación ambiental dada en los libros de texto por un valor de MEC en tres años los años 2013 a 2015 que componen el ciclo de alfabetización. Esto es en el supuesto de que los libros de texto son artefactos culturales que ponen en circulación verdades sobre EA. Por lo tanto, el uso de los 
estudios de Michel Foucault y algunas herramientas de análisis de discurso - expresiones, la verdad y formaciones discursivas. Entendemos que las prácticas discursivas están a la orden del discurso ambiental, reforzando una manera de actuar sobre el medio ambiente y la naturaleza. Dicho trabajo ambiental en líneas subjetividad de temas ecológicos, formando un individuo concatenado en cuando contemporánea. Algunos de los resultados de esta investigación indican la distancia del enfoque transdisciplinario y las expresiones de la circulación que tienen algunos problemas ambientales desde el naturalismo y el discurso de la crisis ambiental.

PALABRAS CLAVE: Educación ambiental. Los libros de texto. Verdad.

\section{INTRODUÇÃ̃o}

Atualmente a preocupação com as questões ambientais são facilmente percebidas na Educação Básica, bem como, no ciclo de alfabetização, através de práticas que se dedicam a pensar sobre as relações com o meio ambiente. Os projetos, de um modo geral, são pensados e articulados em prol da formação de comportamentos ecológicos, amparados, muitas vezes, em uma visão conservacionista. Práticas como a construção de hortas, separação do lixo, plantação de árvores e o cuidado com a biodiversidade são meios de aproximar e problematizar as ações dos seres humanos na natureza.

Tais práticas pedagógicas tornam-se potentes na manutenção do discurso ambiental escolar que aciona o dispositivo da EA, atrelado, muitas vezes, à necessidade de frear a crise ambiental que vivemos na atualidade (GARRÉ e HENNING, 2014). Diante de tal crise, proliferam-se ditos acerca da necessidade premente de aderir a práticas intituladas como ecologicamente corretas.

O "ser e estar" ecológico, na perspectiva de formação do sujeito ecológico, orienta-se por princípios que vão desde medidas individuais, como o consumo ponderado da água ou a reciclagem do lixo, como também almejam alcançar esferas coletivas, que se pautam em posições éticas, legais e políticas, para colocar em funcionamento os valores, decisões e atitudes esperadas dos sujeitos preocupados com a crise ambiental (CARVALHO, 2012). Na operação do discurso da crise ambiental são atingidos também os modos de consumo dos sujeitos ecológicos, o que coloca em evidência as ações de sustentabilidade como marketing publicitário para o consumo de produtos de empresas e indústrias "preocupadas" com a preservação do planeta.

$\mathrm{Na}$ formação do que entendemos por sujeito ecológico o discurso contemporâneo, nos permite aceitar certas maneiras, de agir e pensar em relação à natureza e ao meio ambiente, como verdades incontestáveis que almejam a manutenção e sobrevivência do Planeta. A partir dos estudos de Foucault (2015, p. 54 a) temos entendido o conceito de verdade como

(C) Rev. Educ. Perspec. \begin{tabular}{l|l} 
Viçosa, $M G$ & v.8
\end{tabular}

p.36-53

jan./abr. 2017 eISSN 2178-8359 
"um conjunto de procedimentos regulados para a produção, a lei, a repartição, a circulação e o funcionamento dos enunciados". Desse conceito decorre que, por meio de relações específicas de poder, alguns saberes são legitimados como verdadeiros e outros como falsos.

A obrigatoriedade da ES enquanto tema transversal Meio Ambiente, amparada pelo Parâmetro Curricular Nacional, é uma realidade desde os anos 90, o que demarca a EA como um tema atual e em emergência na sociedade (BRASIL, 1997). Os livros didáticos, sendo materiais disponibilizados pelo governo a professores e alunos da rede pública de ensino, subsidiam propostas ou mesmo materiais para as práticas pedagógicas vinculadas a este campo de saber. Pela amplitude em que a EA apresenta-se nas escolas, parece-nos indispensável pensar sobre os objetivos e ações em que essa vem sendo trabalhada no contexto educacional.

Frente a isso, desenhou-se esta pesquisa. Tomando a EA e a Alfabetização como temas que fundamentam este estudo, construímos como problema de pesquisa: compreender que "verdades" sobre a EA circulantes nesses materiais vêm sendo ensinadas e compartilhadas no ciclo de alfabetização? Como meio de perceber a relevância da formação deste sujeito ecológico já nos primeiros anos do Ensino Fundamental elencamos algumas questões de pesquisa, quais sejam: como se fabrica o sujeito ecológico nas linhas de subjetivação dos livros didáticos em análise? Que ensinamentos sobre natureza e ser humano estão embasando tal concepção?

Para dar conta de responder a este problema de pesquisa, escolhemos como material de análise os livros didáticos recorrentemente utilizados. Através de um mapeamento realizado no Sistema de Material Didático - SIMAD - constatamos que três livros didáticos foram distribuídos em maior número, em escolas gaúchas, para o ciclo de alfabetização.

Os materiais selecionados estão presentes no Plano Nacional do Livro Didático - PNLD - do triênio que correspondem aos anos de 2013, 2014 e 2015, que contemplam o ciclo de alfabetização. Assim sendo, tomamos como corpus empírico três exemplares que foram lidos e analisados por nós.

Com o intuito de problematizar as "verdades" sobre EA presentes nos materiais empíricos fez-se uso de algumas ferramentas foucaultianas relacionadas à Análise do Discurso, sendo essas: enunciações, verdade e formações discursivas.

Este estudo, então, não concebe os conceitos discutidos nos livros didáticos como conjuntos linguísticos ou lógicos pertencentes a uma estrutura de significado e significante, mas concepções relacionadas a fabricações discursivas que produzem o objeto discursivo

\begin{tabular}{l|l|l|l|l|l|l} 
(c) Rev. Educ. Perspec. & Viçosa, $M G$ & v.8 & n.1 & p.36-53 & jan./abr. 2017 & eISSN 2178-8359 \\
\hline
\end{tabular}


implicando ou excluindo conceitos dentro de regras específicas de fabricação. O que analisamos nos Livros didáticos são as enunciações que dão visibilidade a enunciados que constituem as especificidades de determinada formação discursiva (FOUCAULT, 2014). Seu alicerce nas estratégias discursivas permite que os conceitos, fabricados no regime de verdade, atuem entrelaçados na subjetivação de ações e pensamentos coletivos e individuais de sociedades e sujeitos.

Seguindo o acento pós-estruturalista, a presente pesquisa não pretende sugerir a exclusão do uso dos livros didáticos nas escolas. $\mathrm{O}$ que se busca é problematizar as verdades sobre as questões ambientais, percebendo a linguagem a partir do seu papel intermediário, de cunho sociocultural na representação da EA neste potente artefato cultural que circula nas escolas brasileiras, constituindo modos de viver e pensar as questões socioambientais, desde os primeiros anos do Ensino Fundamental. A relevância deste estudo pauta-se, assim, na possibilidade de problematizar algumas enunciações que produzem o campo da EA no contexto escolar, ditos tão bem consolidados que se configuram, muitas vezes, como onipotentes.

A escolha pelo referencial de Michel Foucault, que não separa teoria e método, faz com que o uso de algumas ferramentas da Análise do Discurso paute-se em outro modo de olhar para o material empírico. As ferramentas foucaultianas são potentes nas discussões travadas neste artigo. Na próxima seção se mapeia o aporte teórico-metodológico.

\section{APORTE TEÓRICO-METODOLÓGICO: MAPEANDO ALGUMAS FERRAMENTAS DA ANÁLISE DO DISCURSO}

Para compreender a dinâmica da fabricação de verdades, sua positividade discursiva, no campo da EA, e a presença destas nos livros didáticos, utilizamos algumas ferramentas da Análise do Discurso do filósofo Michel Foucault (2015a), como orientação teórica e metodológica. São elas: enunciações, verdade e formações discursivas.

O autor considera que os discursos são formados por conjuntos enunciativos que se amparam em um sistema de representação, operando enquanto definidores de Regimes de verdade. As formações enunciativas são fabricadas em relações de dependência entre a diferenciação do objeto, em sua materialidade, e na delimitação das estratégias discursivas que operam na dispersão e na regularidade entre os enunciados. Por meio de sua circulação e visibilidade os enunciados poderão formar um único discurso (FOUCAULT, 2014).

\begin{tabular}{l|c|c|c|c|c|c|} 
(C) Rev. Educ. Perspec. & Viçosa, $M G$ & v.8 & n.1 & p.36-53 & jan./abr. 2017 & eISSN 2178-8359 \\
\hline
\end{tabular}


A formação discursiva está apoiada na materialidade das palavras ditas no nível dos enunciados submetidos a uma mesma regularidade e dispersão. A relação entre a formação discursiva e os enunciados é estabelecida de maneira correlativa, enquanto a formação discursiva revela o nível específico dos enunciados, seu nível constitui a individualização das formações discursivas. Nas palavras do filósofo francês:

\begin{abstract}
A lei dos enunciados e o fato de pertencerem à formação discursiva constituem uma e única mesma coisa; o que não é paradoxal, já que a formação discursiva se caracteriza não por princípios de construção, mas por uma dispersão de fato, já que ela é para os enunciados não uma condição de possibilidades, mas uma lei de coexistência, e já que os enunciados, em troca, não são elementos intercambiáveis, mas conjuntos caracterizados por sua modalidade de existência (FOUCAULT, 2015, p. 143 a).
\end{abstract}

Buscamos, portanto, nos Livros Didáticos demarcar as enunciações apresentadas por meio do que é dito e do que é visível. Colocando em evidência as representações de natureza, meio ambiente e seres humanos que objetivam indicar modos de pensar, agir e cuidar do meio ambiente. A materialidade dos enunciados se dá através das enunciações, posto que "uma enunciação pode ser recomeçada e reevocada, enquanto uma forma pode ser reatualizada, o enunciado tem a particularidade de ser repetido: mas sempre em condições estritas" (FOUCAULT, 2015a, p. 128).

Ligada ao discurso científico, a verdade está atrelada a procedimentos específicos de produção. Fabricar verdades não se pauta em ideias utópicas, mas em teses produzidas em meio a relações de poder que as sustentam e as tornam circulantes.

Nos atravessamentos que constituem a dicotomia do que é verdadeiro e do que é falso, do que é aceito e do que deve ser negado, são as relações de saber-poder que possibilitam a construção teórica e conceitual sempre em movimento pelas contradições. Para compreender essas relações precisamos considerar que "[...] poder e saber estão diretamente implicados; que não há relação de poder sem constituição correlata de um campo de saber, nem saber que não suponha e não constitua ao mesmo tempo relações de poder" (FOUCAULT, 2013, p. 30). Os saberes disseminados nos Livros didáticos, por conseginte, são endereçados por meio da indispensabilidade contemporânea de formar sujeitos nas bases do discurso ambiental escolar.

O cenário em que hoje o ciclo de alfabetização está colocado, onde a formação de cidadãos é um dos objetivos pretendidos pelo Ministério da Educação e a emergência das questões ambientais se encontra em ampla circulação nos meios midiáticos e nas Políticas Públicas de modo geral, podemos pensar sobre a possibilidade de constituir crianças em período de alfabetização como sujeitos ecológicos. Isso seria possível a partir das práticas escolares que

\begin{tabular}{l|c|c|c|c|c|c} 
() Rev. Educ. Perspec. & Viçosa, $M G$ & v.8 & n.1 & p.36-53 & jan./abr. 2017 & eISSN 2178-8359 \\
\hline
\end{tabular}


se dedicam às relações entre humano e natureza, meio ambiente, crise ambiental, etc. Estaria aí a produtividade dos livros didáticos que se dedicam a ensinar verdades sobre EA no ciclo de alfabetização? É dessa problematização que trataremos na seção seguinte.

\section{O NATURALISMO tOMAdO COMO ALFABEtizaÇÃo ECOlógica nOS LIVROS DIDÁTICOS SOB ANÁLISE}

Conforme as orientações do Ministério da Educação referente às aprendizagens nos três primeiros anos do Ensino Fundamental, este período, além de abranger os diferentes tempos de aprendizagem no processo de alfabetização e letramento, também está voltado ao trabalho com todas as áreas do conhecimento (BRASIL, 2007). Em meio a este contorno educacional, o Parâmetro Curricular Nacional - Meio Ambiente - (BRASIL, 1997), A Política Nacional da Educação Ambiental (BRASIL, 1999) e outros tantos documentos oficiais que derivam daí, colocam a EA em pauta no cenário educacional.

No contorno atual que vivem professores e alunos, passo a voltar o olhar para os livros didáticos analisados, relembrando que a seleção deste material envolve um material voltado ao $1^{\circ}$ ano de Alfabetização e Letramento, outro do $2^{\circ}$ ano que discute o ensino de ciências e o último livro também de ciências direcionado ao $3^{\circ}$ ano do Ensino Fundamental.

O Livro Alfabetização e letramento ( $1^{\circ}$ ano) apesar de apresentar temáticas referentes à EA, esta é colocada de maneira esvaziada, já que a preocupação está muito mais relacionada ao campo semântico de animais e meio ambiente que embasam atividade de interpretação, conhecimento dos elementos linguiísticos e consciência fonológica. Enquanto que os livros que se pautam no campo da ciência ( $2^{\circ}$ e $3^{\circ}$ anos) voltam-se aos ensinamentos científicos para explicar, apresentar, classificar e discutir questões sobre a crise ambiental, os animais, seus habitats e suas descrições biológicas.

A seleção dos conteúdos e abordagens para cada livro didático demonstra que a EA está distante de seu objetivo educativo por meio de uma visão transdisciplinar. Afirmamos isso, pelo fato de que enquanto no livro de alfabetização e letramento as temáticas de natureza, meio ambiente e animas são exploradas, apenas, como grupos semânticos, nos livros de ciências (para $2^{\circ}$ e $3^{\circ}$ anos) há uma progressiva complexidade quanto às abordagens referentes às questões ambientais. Exemplificando: no $2^{\circ}$ ano são apresentados os hábitos dos animais e posteriormente, no $3^{\circ}$ ano, os animais passam a ser explicados por sua descrição biológica.

(C) Rev. Educ. Perspec.

Viçosa, $M G$

v.8 1 n. 1

p.36-53

jan./abr. 2017

eISSN 2178-8359 
Para que a EA aconteça, em espaços institucionalizados, como a escola, não basta abordar um tema que pertença a seu campo discursivo, tampouco simplificar a sistematização de abordagens que se preocupam, unicamente, com classificações e conceitos.

A EA utiliza-se dos conteúdos da área das ciências naturais, sociais e exatas para compreender a interação entre natureza e cultura. De acordo com Marcos Reigota (2014, p. 64) "Os conceitos científicos [...] têm por função fazer o elo entre a ciência e a temática ambiental cotidiana" e não definir a EA como mais um conteúdo das ciências naturais. O elo referido pelo autor, entre a ciência e as questões ambientais, está na ordem da interação entre sociedade e ambiente. A EA está embasada nas interações ecossistêmicas e socioculturais. Portanto, não se trata de abordá-la enquanto um campo puramente ecológico, permeado de uma concepção naturalista, que coloca a natureza em oposição à sociedade, mas sim, ampliála para as relações que se estabelecem entre ser humano e natureza, sociedade e ambiente.

A concepção que se apresenta nos três livros didáticos, interpelada pelo discurso da crise ambiental, demonstra a necessidade de formar as crianças para agirem em prol da sustentabilidade. Neste momento, é possível perceber o discurso ambiental escolar articulado ao da crise operando na formação de sujeitos ecológicos. Como aponta Isabel Cristina Carvalho (2012), a base para a formação destes sujeitos está na mudança de atitudes dos valores éticos.

Há de ser ratificado que nem sempre discorrer e discutir sobre temas ambientais significa uma prática de Educação Ambiental. Esta afirmativa se pauta pelas abordagens trazidas no livro Alfabetização e Letramento voltado ao $1^{\circ}$ ano (BORGATTO; BERTIN; MARCHEZI, 2011), que apesar de versar em grande quantidade sobre os animais, seus ensinamentos estão esvaziados em histórias, cantigas e atividades, que em nada contemplam as questões ambientais, já que estão voltadas apenas às práticas alfabetizadoras.

A presença da personificação é uma prática recorrente nesse livro didático que demonstra a ausência da relação entre o foco do livro - alfabetização e letramento - com as discussões da EA. Esta assertiva pode ser observada no excerto abaixo (BORGATTO; BERTIN; MARCHEZI, 2011, p. 113):

\footnotetext{
A galinha pintadinha

E o galo carijó

A galinha veste saia

E o galo paletó
}

A figura de linguagem é apresentada em contos, cantigas, parlendas e pequenas histórias que atribuem aos animais características e qualidades humanas. Na recorrência de personificar os animais, não há qualquer aprofundamento sobre as relações entre as crianças e os animais. $\mathrm{O}$

n.1
p.36-53 
leão é apresentado na letra da música abaixo a partir da morte de outro animal. Não estaria neste artefato cultural a produtividade de problematizar com as crianças as representações que colocam a natureza, ora como o ideal de harmonia, ora como cruel? Vejamos o exemplo extraído do livro (BORGATTO; BERTIN; MARCHEZI, 2011, p. 139):

\author{
O Leão ${ }^{\text {iv }}$ \\ Leão! Leão! Leão! \\ Rugindo como um trovão \\ Deu um pulo, e era uma vez \\ Um cabritinho Montês
}

$\mathrm{Na}$ compreensão, compartilhada com a autora Maria Wortmann (2010), de que as representações que disseminamos e os meios que adotamos para nos relacionarmos com a natureza são fabricações sociais e culturais (WORTMANN, 2010), é possível afirmar, que ao desconsiderar as reflexões suscitadas pela relação entre o ser humano e o meio ambiente, o livro didático demonstra certo distanciamento das abordagens referentes à EA, enquanto um campo de provocações políticas.

Trazer a fauna e a flora para histórias, cantigas e atividades alfabetizadoras não evidencia a complexidade das relações entre os seres humanos e o meio natural. O esvaziamento de discussões acerca das questões ambientais com o uso das parlendas, cantigas e músicas as atividades que dessas derivam evidencia a ausência de aprofundamentos políticos, éticos e sociais referentes às representações ambientais e aos ensinamentos sobre animais.

Trazer o tema sobre os animais, a natureza ou o meio ambiente não garante a transversalidade esperada pelo Parâmetro Curricular Nacional. A questão que se pauta não é de dizer qual ensinamento é mais importante, se as práticas alfabetizadoras ou as discussões ambientais, mas sim a possibilidade produtiva da transversalidade da EA nos livros didáticos. A transdisciplinaridade que se espera no âmbito escolar da EA, compreende que esta "[...] pode estar presente em todas as disciplinas, quando analisa temas que permitam enfocar as relações entre a humanidade e o meio natural e as relações sociais, sem deixar de lado as suas especificidades" (REIGOTA, 2014, p. 45).

Enquanto uma recorrência do livro Alfabetização e Letramento do $1^{\circ}$ ano, o livro de Ciências direcionado ao $2^{\circ}$ ano do Ensino Fundamental também traz a temática dos animais, todavia seus ensinamentos estão voltados aos hábitos destes. A área permitida para apresentar alguns aprofundamentos sobre os animais é a ciência, como a Modernidade nos ensinou. Na linha teórica que segue esta pesquisa, o regime de funcionamento das verdades na sociedade moderna, está articulado ao discurso científico para legitimá-las e colocá-las em circulação por meio dos enunciados e enunciações (FOUCAULT, 2015b).

n.1 p.36-53


As duas assertivas extraídas do livro de ciências voltado ao $2^{\circ}$ ano (NIGRO; CAMPOS, 2011a, p. 137) apresentam a produção de conhecimentos voltados aos hábitos dos animais distanciada da relação destes com a sociedade, atrelando-se a legitimidade do campo científico.

1) O morcego dorme de dia e se torna ativo à noite. Já o cachorro é um animal de hábito diurno.

2) Noturno ou diurno?

Você já viu morcegos e mariposas voando por aí em plena luz do dia?

O mais provável é que não. È que esses animais procuram comida e alimentam-se preferencialmente de noite. Mais ativos durante a noite, eles são considerados seres vivos de hábitos noturnos.

Mas, ao contrário deles, há seres vivos que são mais ativos durante o dia. São os seres vivos de hábitos diurnos.

Mesmo apresentando os hábitos de animais diurnos, como os cachorros que convivem diariamente com os seres humanos, a discussão sobre esta interação entre homem-cachorro é inexistente. Em artefatos culturais como cinema, propagandas, livros infantis e até mesmo em romances da literatura deparamo-nos com a fabricação de discursos que nos mostram certas formas de conduta perante o meio natural e animal, relação que é apagada pela legitimidade e superioridade conferida à ciência, desde a modernidade.

A EA é abordada pelo esvaziamento político das explicações biológicas dos animais, descolada das relações sociais e culturais, demarcando a visão de uma vertente naturalista.

Com tudo isso que nos deparamos, é possível pensar na inexistência da transversalidade da EA nos livros analisados, uma vez que os livros evidenciam elementos da natureza, mas sem problematizar o campo político da EA.

Para além da inexistência da transversalidade da EA esta, conforme está sendo tratada em grande parte nos três livros didáticos, se confunde a uma vertente integrante apenas das ciências biológicas, num caráter ecológico difundido na emergência da EA, na década de 60, em que os movimentos ecológicos eram compostos principalmente por biólogos e ecologistas.

A presença do discurso da crise ambiental, que hoje movem muitas das práticas de EA, estando divulgado e disseminado em diferentes artefatos culturais também é recorrente no livro de ciências $-2^{\circ}$ Ano.

É possível perceber, nas atividades que procuram problematizar os diferentes ambientes e suas características, o endereçamento de uma culpa ao homem pela degradação ambiental. Por meio de interrogativas que questionam sobre a presença dos seres vivos através de suas

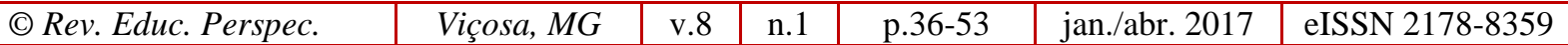


ações no meio ambiente, vê-se proliferar a ideia de que o humano é o culpado pela crise ambiental que se instaurou.

Em dois momentos nos deparamos com enunciações visíveis que apresentam as ações do homem como responsáveis pela degradação do meio ambiente. Essas estão direcionadas a representarem à produção e ao depósito inadequado do lixo. $\mathrm{Na}$ primeira imagem a enunciação está representada com a grande quantidade de lixo depositado à beira do rio (NIGRO; CAMPOS, 2011, p. 38 a); a segunda igualmente aborda a temática do lixo, porém no pé e nas folhas de uma árvore (NIGRO; CAMPOS, 2011a, p. 48).

As imagens descritas acima estão em posição relacional com duas perguntas que as antecedem respectivamente imagens, são elas: "Você cuida bem do ambiente?" (NIGRO; CAMPOS, 2011, p. 38 a) e "Como temos cuidado do nosso entorno?" (NIGRO; CAMPOS, 2011a, p. 48). O enfoque de ambas é a respeito da produção de lixo demasiada, sem nos preocuparmos com a reutilização dos produtos possíveis de serem reciclados e reutilizados, descartando os resíduos de maneira inadequada. A pergunta mote é endereçada a nós, seres humanos. Tais enunciações operam, nestas circunstâncias, na circulação do enunciado de sustentabilidade que direciona a problemática ambiental como meio de capturar as crianças para agirem na campanha planetária de salvação do Planeta.

As enunciações tendem a abordar a importância de práticas como reciclar o lixo para a sobrevivência do planeta. Com isso, também refletem sobre as visões do ser humano na natureza, e que este, por ser culpado da degradação ambiental, tem por obrigação cuidar de maneira sustentável do meio ambiente para garantir sua própria sobrevivência. Tal ação é recorrente no livro didático de ciências voltado ao $2^{\circ}$ ano. Ali, há um alerta sobre a crise ambiental, explicando-a, prevendo seus possíveis acontecimentos e trazendo suas soluções por meio da ação do ser humano.

Seguindo a abordagem pós-estruturalista dos estudos de Michel Foucault (2015a) a imagem apresentada tem sua significação na circulação de enunciações que coloca em operação o discurso da crise ambiental. Assim, produz modos de enxergar a relação entre o ser humano e a natureza, subjetivando os indivíduos, por meio da fabricação de verdades que legitimam a problemática ambiental, enquanto uma consequência das ações dos seres humanos. Isso reverbera, de forma incisiva, que os culpados pela crise que se instaurou, devido a sua má condução, devem agir para a sustentabilidade do planeta.

A proliferação de enunciados que operam na circulação do discurso da crise ambiental está engajada na formação de sujeitos ecológicos. Sendo assim, é possível afirmar que a EA

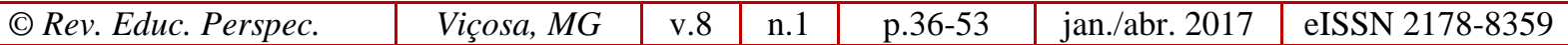


acontece no livro didático do $2^{\circ}$ Ano como uma prática de conscientização, através da preocupação com a crise ambiental. Conforme aborda Bárbara Garré (2015, p. 60):

\begin{abstract}
A própria Educação Ambiental se constitui através de uma visão catastrófica e apocalíptica. Ao olhar sua constituição, identifico que sua emergência se dá a partir de uma preocupação mundial com as alterações realizadas no meio ambiente. Dessa forma, a EA se constrói historicamente a partir de uma concepção de problema e de crise, na qual é necessário aliar forças para salvar o Planeta. Isto se torna visível quando voltamos nossa atenção para os grandes encontros e conferências mundiais que desencadearam a EA enquanto um campo de saber.
\end{abstract}

Conceituar, explicar e compreender as relações e objetos a nossa volta são práticas subjetivadas pelos discursos. O que entendemos por crise ambiental, meio ambiente, cultura e natureza, são ensinamentos que advêm das verdades produzidas e circuladas socialmente. Portanto, o discurso que se prolifera na escola está circulante na sociedade, o que reverbera a EA para além das instituições escolares.

Compreendendo que os artefatos midiáticos e escolares são parte fundamental para o funcionamento da circulação dos discursos ambientais e suas verdades, analisamos o poema Zoológico (NIGRO; CAMPOS, 2011b, p. 28) presente no livro didático de ciências voltado ao $3^{\circ}$ ano do Ensino Fundamental.

\author{
Zoológico \\ Assim é hoje em dia \\ O zoológico que se afirma \\ Neste zoológico o que se avista \\ É a liberdade à vista \\ Animais em pequenas jaulas, não! \\ Você sabe onde eles estão? \\ Em amplos recintos criados \\ Para que todos possam ser admirados \\ Onças e gaviões com espaço \\ Peixes, sapos e jacarés lado a lado \\ Assim é hoje em dia \\ $\mathrm{O}$ zoológico que se afirma \\ Neste zoológico o que se avista \\ É a liberdade à vista.
}

O poema apresenta o zoológico enquanto um local de cuidado com os animais que nele residem "Em amplos recintos criados/Para que todos possam ser admirados". Nestes dois versos do poema é possível compreender que o zoológico está sendo visto como um ambiente de cuidado pensado por seres humanos, para abrigar os animais e, consequentemente, possibilitar que sejam admirados. 
Para alguns autores, no campo da EA, este lugar é compreendido como cumpridor de funções socioeducativas, estreitando os laços entre as crianças e os animais, e potencializador das discussões sobre as questões ambientais. Ambas as afirmativas são compartilhadas por Fabíola Fonseca e Leandro Oliveira (2011) "O zoológico é um ambiente que tem um enorme potencial educativo em que existe a possibilidade de entrelaçar a curiosidade ao lúdico [...]”.

Por outro lado, há autores como Rafael Souza e Letícia Albuquerque (2015) que consideram o zoológico um local demonstrador do antropocentrismo, que retira os animais de seu habitat natural para mantê-los em cativeiro como meio de entreter e/ou educar os sujeitos aproximando-os da "natureza".

Concordamos com o posicionamento dos autores ao analisar estes espaços como demonstradores da relação antropocêntrica entre ser humano e natureza. A questão dos zoológicos, diferentes dos locais de acolhimento de animais silvestres, é de que estes são formados a partir de animais que teriam plenas condições de viver em seus habitats naturais se não fossem mantidos desde filhotes em cativeiros. A razão, mais uma vez, pauta-se em colocar o ser vivo civilizado como ser superior e distanciado da "natureza", já que sua civilização permite manter os animais alimentados e bem cuidados, segundo a visão humana.

Ainda é possível perceber neste livro (NIGRO; CAMPOS, 2011b, p. 32) a recorrência de ensinamentos de conceitos que classificam os animais a partir de suas características biológicas em categorias. Os conceitos fabricados e legitimados pelo discurso científico são produtos de verdades que dão conta de explicar e classificar os animais por meio de características fisio-biológicas.

1) Mamíferos: animais que geralmente possuem uma espessa camada de pelos revestindo quase todo o corpo; seus filhotes mamam.

2) Aves: animais com asas, pernas traseiras, pele revestida de penas, boca prolongada em bico, sem dentes; a fêmea põe ovos.

Vimos a produção de verdades que explicam e dividem os animais em categorias a partir de suas características e hábitos. Apesar das discussões do livro didático de ciências do $2^{\circ}$ ano se diferenciar, ao referirem-se as problemáticas da crise ambiental e no conteúdo a temática dos animais, ambos os livros de ciências $-2^{\circ}$ e $3^{\circ}$ anos -, estão deslocados da concepção de uma EA voltada para as relações socioambientais. Os conhecimentos científicos são apresentados de maneira que recaem sobre as concepções de ambiente e natureza com uma visão puramente física e biológica. Para Isabel Carvalho (2012, p. 81):

Não se trata aqui de negar a importância do conhecimento e das explicações biológicas na EA, mas de alertar para o risco de reduzir o ato educativo a um repasse de informações provenientes das ciências naturais, sem correlacionar esse conhecimento com a complexidade das questões sociais e ambientais que o circundam e o constituem.

Seja por meio da atribuição de ações e características humanas aos animais, como é o caso das parlendas presente no livro didático do $1^{\circ}$ Ano -, ou pela categorização dos animais por

(C) Rev. Educ. Perspec.

\begin{tabular}{l|l} 
Viçosa, $M G$ & v.8
\end{tabular}

\begin{tabular}{l|l|l|l} 
n. 1 & p.36-53 \\
\hline
\end{tabular}

jan./abr. 2017

eISSN 2178-8359 
meio da ciência que os explicam e conceituam, como é o caso dos ensinamentos dos hábitos e das classificações dos animais - demarcado nos livros didáticos do $2^{\circ}$ e do $3^{\circ}$ Anos -, continuamos a permanecer em uma relação de controle da natureza. Segundo mostram os livros didáticos, a preocupação escolar está em transmitir os conhecimentos e suas verdades legitimadas sobre as condições fisio-biológicas do meio ambiente e seus impactos sofridos pela ação humana. $\mathrm{O}$ que queremos provocar aqui é a premência da escola evidenciar as relações entre o social e o dito natural. Talvez valesse pensar para além dos conhecimentos científicos estanques, mas provocar seus alunos a pensar nas estreitas relações entre as questões culturais e a suposta natureza intocável.

A tentativa dos livros didáticos de ciências $-2^{\circ}$ e $3^{\circ}$ anos - está em naturalizar o meio ambiente, enquanto um ambiente de vida selvagem, contemplado de fauna e flora. Esta afirmativa, para alguns leitores, pode ser familiar, afinal é comum vermos em artefatos midiáticos tais representações de natureza intocada e meio ambiente como base de relações ecossistêmicas em perfeita harmonia, se o ser humano dali permanecer distante. Conforme Isabel Carvalho (2012) são representações como estas que caracterizam o naturalismo enquanto uma vertente da EA, que desarticula as relações ecossistêmicas das interações socioculturais.

O naturalismo, movido pelos movimentos ecológicos da década de 60 do século XX, explora o ideário de cuidado com a natureza a partir do distanciamento do ser humano, que entendido como fora da harmonia do ambiente natural, é visto como parte de uma civilização que degrada e prejudica a natureza. Visões como estas analisam a natureza e o meio ambiente a partir das relações ecossistêmicas, de uma ecologia puramente biológica que procura caracterizar, classificar, ordenar e conceituar espécies de animais irracionais e vegetais para buscar sua proteção e conservação.

Podemos afirmar que os discursos presentes nos três livros didáticos estão de encontro ao que atualmente a EA busca: consolidar-se como um campo de saber para além de uma ciência puramente ecológica, mas também, rica em vertentes e interações sociais e culturais (REIGOTA, 2014). O esvaziamento político do campo de saber da EA precisa ser repensado por nós, enquanto alfabetizadoras contemporâneas.

\section{ATRAVESSAMENTOS ENTRE O DISCURSO AMBIENTAL E OS LIVROS DIDÁTICOS NA FORMAÇÃO DE SUJEITOS ECOLÓGICOS}

Nos dias atuais a EA está presente em diversos meios midiáticos, que segundo a perspectiva dos estudos culturais, ensinam e educam crianças, jovens, adultos e idosos a adotar comportamentos e atitudes ecologicamente corretas embasadas, principalmente, na concepção de sustentabilidade do planeta. Artefatos culturais que apresentam concepções de 
natureza, sociedade, meio ambiente, além de apresentarem os problemas e possíveis soluções para a crise ecológica.

Partilhando da abordagem dos Estudos Culturais ${ }^{\mathrm{v}}$, os artefatos midiáticos e escolares estão sendo compreendidos como artefatos culturais, ferramentas e veículos que põem em circulação enunciados de diferentes segmentos, que produzem subjetividades e identidades que orientam nossos modos de viver. A característica destes artefatos de possibilitar ensinamentos e representações é entendida, a partir da perspectiva dos Estudos Culturais, como Pedagogia Cultural.

O grande enfoque dado à preocupação com a formação de sujeitos educados para o cuidado com o meio ambiente traz ao sistema educacional as discussões que permeiam a EA, enquanto um campo voltado a práticas sociais preocupadas com as relações entre sociedade e ambiente. Certamente, este campo de saber carrega consigo implicações políticas e modos de subjetivação.

A formação dos sujeitos ecológicos está fortemente associada à crise ambiental, vista enquanto um problema causado pela humanidade que deve ser reparado pela mesma. Esta tomada de consciência não paira apenas sobre educadores ambientais, ecologistas e ativistas. A atual evidência das questões ambientais equiparadas ao ideário da constituição de um sujeito ecológico está embasada na possibilidade de reorganização social, na esperança de formar uma sociedade com bases sustentáveis que possibilite experiências de bem-estar, felicidade e harmonia (CARVALHO, 2012).

Por compreender o caráter constitutivo das verdades e por analisar a escola como uma instituição propagadora dos discursos aceitos na sociedade, a presente pesquisa analisa os livros didáticos como ferramentas, que colocam em operação a circulação de verdades relacionadas ao campo da EA. A escola, assim como a sociedade, é constituída por discursos que, muitas vezes, assumimos como legítimos. As verdades que movem as práticas escolares são resultados do que já é aceito e circulante no meio social. Por isso as verdades professadas nos livros didáticos não estão apenas em circulação no âmbito escolar, mas imiscuídas na sociedade.

A EA pensada como uma vertente política a partir de meados dos anos 1970, articula-se a intervenções que perpassam as áreas sociais, culturais, históricas e científicas. Atualmente, não se trata mais de pensá-la na restrição de minorias de amantes da harmonia natural, ou mesmo enquanto uma ciência ecológica preocupada apenas com a relação dos seres vivos em seus habitats, mas pensar a EA articulada a discursos, práticas, ações e visões que viabilizam outros modos de lidar com a humanidade e o ambiente.

n.1 p.36-53


Diante desta realidade vemos formar-se um novo sujeito na contemporaneidade, efeito das subjetivações consequentes dos discursos envoltos na EA. Esse sujeito em formação é capturado pelos discursos referentes à crise ambiental em ampla circulação na sociedade.

São as verdades proferidas e circulantes, em artefatos culturais, que nos denotam sentidos e modos de comportamentos, impulsionadores de estilos de vida, modos de pensar e agir perante a natureza e o meio ambiente, que envolve a fabricação dos sujeitos ecológicos. De acordo com Leandro Guimarães e Shaula Sampaio (2004), os processos de representações presentes nos artefatos culturais operam modos de subjetivação por meio das relações de poder que lhe concedem a legitimação e que permitem sua suposta naturalização.

A apropriação social dos discursos que compõem a EA é fabrica linhas de subjetivação que constituem um determinado sujeito moderno e ecológico. A marca moderna da cientificidade está presente nos Livros didáticos demarcando formas tidas como corretas de entender e relacionar-se com o meio ambiente e a natureza. No entrelaçar da positividade das relações de saber e poder que produzem os sujeitos ecológicos e das teias problematizadoras da EA no contexto educacional é que concluímos, na seção seguinte, as principais considerações da pesquisa.

\section{CONCLUSÃO}

A organização de conteúdos dos livros didáticos ampara-se, por vezes, em um distanciamento da concepção que compreende as relações ecossistêmicas como parte formadora e formada na interação com a sociedade e sua cultura. A visão naturalista presente nos livros de ciências coloca a EA enquanto uma vertente apenas das ciências biológicas e ecológicas, na qual a preocupação está em classificar, explicar e definir a natureza, o meio ambiente e os seres vivos. Apenas quando trata da crise ambiental, é evidenciada certa discussão atrelada à atualidade. Ainda assim, vale dizer, demarcando o ser humano como o degradador e responsável pelas devastações ambientais. As enunciações que culpam o ser humano, igualmente o convidam para participar da campanha de salvação do planeta, com a modificação de atitudes e comportamentos orientados por uma consciência ecológica.

As formas de abordar a EA, as representações de natureza, meio ambiente e animais, os saberes legitimados no discurso científico, a posição em que os seres humanos são concebidos como a causa e a solução para as problemáticas ambientais e as atitudes que se esperam deles perante a crise ecológica são modos de constituir sujeitos ecológicos no interior do discurso ambiental escolar. Meios de produção cultural que fomentam um ideal de sociedade. 
Mesmo nos deparando com uma EA, ora esvaziada por grupos semânticos, ora sendo concebida nos livros didáticos como um conteúdo exclusivo da ciência. Pensamos na potência de problematizações não realizadas nos Livros didáticos. Potencialidade evidente nos Parâmetro Curricular Nacional - Meio Ambiente, enquanto um tema transversal, atrelado a diferentes conhecimentos e relações (BRASIL, 1997), como também pelos próprios pesquisadores do campo que a discutem a partir de uma visão socioambiental (CARVALHO, 2012; REIGOTA, 2014), ou mesmo por uma visão ecosófica (GUATTARI, 2012).

Nas linhas desta pesquisa, que buscou colocar em suspenso as verdades sobre EA presentes nos livros didáticos de alfabetização, evidenciamos abordagens de EA reducionistas e, muitas vezes, marcadas pela vertente teórica naturalista. Nos livros de ciências, tal vertente é permeada por enunciações do discurso da crise ambiental. No livro do primeiro ano os temas do campo semântico ambiental estão associados à personificação da fauna por mera característica linguística. De uma forma ou de outra, consta a EA, nos livros didáticos, descolada de uma abordagem transdisciplinar.

\section{REFERÊNCIAS}

BORGATTO, Ana Trinconi; BERTIN, Terezinha; MARHEZI, Vera. Ápis: Letramento e Alfabetização. 1 ed. São Paulo: Ática, 2011.

BRASIL. Ministério da Educação. Ensino Fundamental de Nove Anos: orientações para a inclusão da criança de seis anos de idade. 2.ed. Brasília: 2007.

BRASIL. Lei 9.795 de 27 de abril de 1999. Dispõe sobre Educação Ambiental, institui a Política Nacional de Educação Ambiental. Brasília, DF, 27 abr. 1999. Disponível em: <http://www.planalto.gov.br/ccivil_03/leis/19795.htm>. Acesso em: 4 nov. 2016.

BRASIL. Apresentação dos temas transversais, meio ambiente. Brasília: MEC/SEF, 1997. Disponível em: <http://portal.mec.gov.br/seb/arquivos/pdf/livro081.pdf>. Acesso em: 4 nov. 2016.

CARVALHO, Isabel Cristina de Moura. Educação ambiental: a formação do sujeito ecológico. 6.ed. São Paulo: Cortez, 2012.

FONSECA, Fabíola Simões Rodrigues da; OLIVEIRA, Leandro Gonçalves. Concepções de meio ambiente dos educadores ambientais do Zoológico de Goiânia: implicações nas atividades e contribuições para a formação do sujeito ecológico? Educar em Revista. n. 41, Curitiba: Editora UFPR, p. 231-246, jul./set., 2011. Disponível em:

<http://www.redalyc.org/articulo.oa?id=155021076015>. Acesso em: 4 nov. 2016.

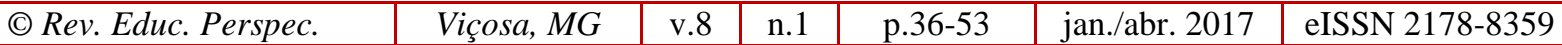


FOUCAULT, Michel. Arqueologia do saber. 8. ed. Rio de Janeiro: Forense Universitária, 2015a.

FOUCAULT, Michel. Microfísica do poder. 2. ed. Rio de Janeiro: Paz e Terra, 2015b.

FOUCAULT, Michel. A ordem do discurso: aula inaugural do Collège de France, pronunciada em 2 de dezembro de 1970. 24 .ed. São Paulo: Edições Loyola. 2014.

FOUCAULT, Michel. Vigiar e punir: nascimento da prisão. 41.ed. Petrópolis: Vozes, 2013.

GARRÉ, Bárbara Hees. O dispositivo da educação ambiental: modos de constituir-se sujeito na revista Veja. Rio Grande, 2015. 185 f. Tese (Doutorado em Educação Ambiental) Universidade Federal do Rio Grande. Programa de Pós-Graduação em Educação Ambiental.

GARRÉ, Barbara Hees; HENNING, Paula Corrêa. Modos de atualizar o enunciado catastrófico do Planeta Terra na Revista Veja. ETD - Educação Temática Digital, Campinas, SP, v. 16, n. 3, p. 426-439, set./dez. 2014. Disponível em: 〈https://periodicos.sbu.unicamp. br/ojs/index.php/etd/article/view/1307>. Acesso em: 4 nov. 2016.

GUATTARI, Félix. As três ecologias. 21.ed. Campinas: Papirus, 2012.

GUIMARÃES, Leandro Belinaso; SAMPAIO, Shaula Maria Vicentini. Praticando Estudos Culturais em articulação com a Educação Ambiental. In: ZAKRZEVSKI, Sônia Balvedi; BARCELOS, Valdo. (Org.). Educação ambiental e compromisso social. Erechim: EdiFAPES, p. 125-146, 2004.

NIGRO, Rogério G.; CAMPOS, Maria Cristina da C. Ápis: Ciências $2^{\circ}$ ano. São Paulo: Ática, v. 1, 2011a.

NIGRO, Rogério G.; CAMPOS, Maria Cristina da C. Ápis: Ciências $3^{\circ}$ ano. São Paulo: Ática, v. 2, $2011 \mathrm{~b}$.

REIGOTA, Marcos. O que é educação ambiental. 2.ed. São Paulo: Brasiliense, 2014.

SOUZA, Rafael Speck de; ALBUQUERQUE, Letícia. Sobre o olhar antropocêntrico: o ser humano e o jardim zoológico. Revista Internacional Interdisciplinar INTERthesis, v. 12, jan./jun. 2015. Disponível em: https://periodicos.ufsc.br/index.php/interthesis/article/ view/1807-1384.2015v12n1p117/29655 . Acesso em: 4 nov. 2016.

WORTMANN, Maria Lúcia Castagna. A Educação Ambiental em perspectivas culturalistas. In.: CALLONI Humberto; SILVA, Paulo Ricardo Granada (Org.). Contribuições à educação ambiental. Pelotas: Editora Universitária/UFPel, p. 13-37, 2010. 


\begin{abstract}
' Lorena Santos da Silva - Mestranda no Programa de Pós-graduação em Educação Ambiental na Universidade Federal do Rio Grande. E-mail: lory.lorenasantos@gmail.com

ii Paulo Corrêa Henning - Professora Adjunta do Instituto de Educação, do Programa de Pós-graduação em Educação em Ciências e do Programa de Pós-graduação em Educação Ambiental da Universidade Federal do Rio Grande. Mestre em Educação pela Universidade Federal de Pelotas e Doutora em Educação pela Universidade do Vale do Rio dos Sinos. E-mail: paula.c.henning@gmail.com

iii Virgínia Tavares Vieira - Mestre em Educação Ambiental pela Universidade Federal do Rio Grande - FURG e atualmente doutoranda no Programa de Pós-graduação em Educação Ambiental na Universidade Federal do Rio Grande. E-mail: vi_violao@yahoo.com.br
\end{abstract}

\title{
NOTAS:
}

${ }^{\text {iv }}$ Vinicius de Moraes e Fagner. O Leão. Cd Arca de Noé 2. Polygram, 1981. Faixa 2.

v Este campo compõe-se de perspectivas analíticas que buscam compreender as formas de produção e disseminação de representações que reverberam as relações de poder na sociedade. Em intersecção com a EA, os Estudos Culturais têm se debruçado sobre as representações de natureza e meio ambiente, produzidas e disseminadas em diversos artefatos que operam nas linhas de subjetivação dos sujeitos (GUIMARÃES; SAMPAIO, 2004).

Submetido em: 04-11-2016 - Aceito em: 08-05-2017.

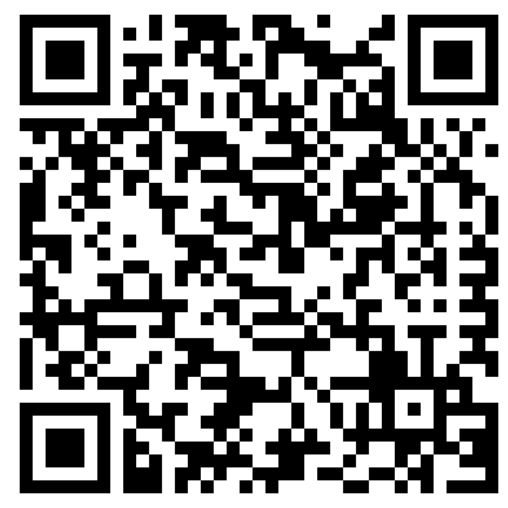

